\title{
Akuntansi BUMDes di Desa Je'nemadinging Kabupaten Gowa
}

\author{
Asbi Amin ${ }^{\mathrm{a}, 1, *}$, Niken Probondani Astuti ${ }^{\mathrm{b}, 2}$ \\ a,b Akuntansi, Manajemen, STIEM Bongaya \\ ${ }^{1}$ asbi.amin@stiem-bongaya.ac.id *; ${ }^{2}$ niken.probondani@stiem-bongaya.ac.id \\ * corresponding author
}

\section{ARTICLE INFO}

\section{Article History}

Received,11-11-2020

Revised,24-12-2020

Accepted,16-01-2021

Keywords

Accounting;

Financial Reports

\begin{abstract}
Je'nemadinging village is one of the villages located in Pattalassang District, Gowa Regency. Since the existence of BUMDes in this area, all these transactions are only recorded when money comes in and money goes out with a simple count. BUMDes managers have never prepared financial reports as appropriate for a business-oriented entity. This is due to the lack of knowledge of managers because none of their educational backgrounds come from the economic sector. On the basis of the problems that occur with partners, this PKM program needs to be carried out. This PKM activity was carried out at the Je'nemadinging village office. The model used in the lecture method, tutorial method and discussion. The result of this PKM is that the BUMDes Management can make bookkeeping in the form of recording incoming and outgoing money in accordance with generally accepted rules. In addition, BUMDes management has understood the accounting for cash receipts, cash disbursements, sales and purchases to the preparation of financial reports
\end{abstract}

\section{PENDAHULUAN}

Beberapa perdebatan yang muncul terkait pengelolaan Badan Usaha Milik Desa (BUMDes), mulai dari keterbatasan pengelola dana desa dan kapasitas pengelolaan yang tidak siap hingga benturan kepentingan yang mendominasi pengelolaan BUMDes. (Ferina, Hanila, Fitriano, Susanti, \& Soleh, 2020). BUMDes merupakan salah satu pilar pembangunan pedesaan yang dibentuk untuk meningkatkan kesejahteraan masyarakat pedesaan (Wirsa \& Prena, 2020).

BUMDes telah berkembang pesat di Indonesia. Namun, sayangnya sasaran perkembangan belum tepat sasaran dan jauh dari tujuan pemerintah. Dana BUMDes saat ini belum optimal dan belum memberikan kontribusi yang diharapkan oleh masyarakat desa. Di beberapa desa di Indonesia, pembentukan BUMdes terkesan hanya sebagai formalitas karena belum terlihat peran aktifnya dalam mencapai tujuan pembentukan BUMDes tersebut.

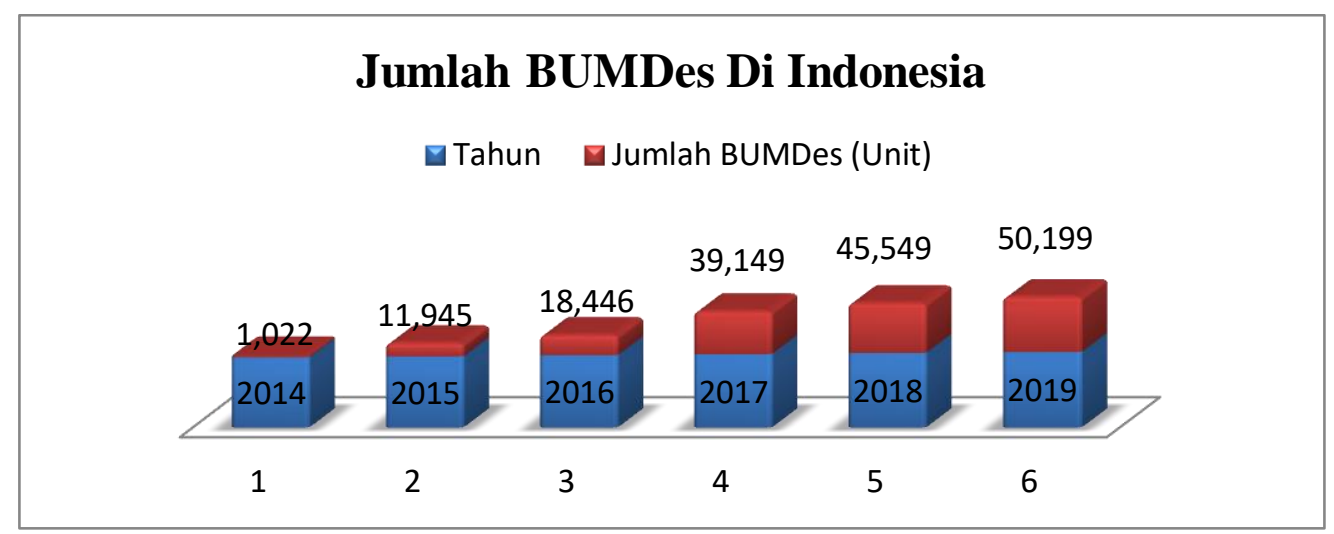

Gambar 1. Jumlah BUMDes di Indonesia

Sumber : Menteri Desa, Pembangunan Daerah Teringgal \& Transmigrasi (Mendes PDTT)

Data perkembangan BUMDes di Indonesia yang bertambah setiap tahun namun tidak dibarengi dengan laporan kinerja dan laporan keuangan yang transparan. Padahal desa dituntut wajib 
melaporkan aktifitas keuangannya sesuai dengan ketentuan yang ditetapkan. (Undang-Undang No.6, 2014). Laporan keuangan berguna memberikan informasi kepada pihak berkepentingan untuk acuan pengambilan keputusan (Suryani, 2018) karena laporan keuangan dapat mencerminkan struktur permodalan dan laba rugi BUMD (Ferina, Hanila, Fitriano, Susanti, \& Soleh, 2020).

Akuntansi sebagai sistem informasi yang akan menghasilkan laporan keuangan. BUMDes juga harus mencatat secara sistematis transaksi yang terjadi setiap hari. Transaksi ini biasanya dicatat dengan menggunakan sistem akuntansi.. (Nurniah, Sukriah, \& Istiyana, 2019). (Mispiyanti, 2020) menyatakan bahwa pencatatan akuntansi pada dasarnya terdiri dari dua metode, yaitu sistem kas dan sistem akrual. Kedua metode akuntansi tersebut berbeda dalam prinsip akuntansi umum.

Akuntansi desa berbeda dengan pengelolaan keuangan desa. Dalam pengelolaan keuangan desa terjadi kegiatan kompleks mulai dari merencanakan, melaksanakan, melaporkan dan mempertanggungjawabkan keuangan desa. Sedangkan akuntansi desa memberi informasi laporan keuangan BUMDes yang setidaknya meliputi empat komponen yakni harta, utang, biaya dan pendapatan yang disertai dengan bukti-bukti transaksi yang ada (Mahmudah, 2018).

Dibutuhkan kapasitas dari pengelola bumdes untuk dapat menyelesaikan tugas dan tanggungjawabnya menyusun laporan keuangan. Kapasitas pengelola ini bisa dimiliki oleh pengelola dari pendidikannya, dari pelatihan yang telah diikutinya atau dari pengalamannya (Anwar \& Amin, 2020). Namun, faktanya pemahaman pengelolaan keuangan dan akuntansi BUMDes didesa Jene' maddinging masih kurang.

Desa Jene'madinging yang terletak di Kecamatan Pattalassang, Kabupaten Gowa dihuni oleh puluhan penjual burasa' dan berada pada golongan ekonomi rendah. Sejak adanya BUMDes beberapa warga desa diberikan modal simpan pinjam untuk membuat usaha penjualan bensin atau Pertamini didepan rumah, mereka menyetorkan uang hasil penjualan pertamini tersebut ke BUMDes sesuai perjanjian saat peminjaman. Semua transaksi tersebut hanya dicatat saat uang masuk dan uang keluar saja dengan hitungan sederhana. Pengelola BUMDes belum pernah membuat laporan keuangan selayaknya dibuat oleh satu badan berorientasi bisnis. Hal ini disebabkan kurangnya pengetahuan pengelola karena latar belakang pendidikan yang tidak satupun yang berasal dari bidang ekonomi.

Penelitan (Nugrahaningsih, Falikhatun, \& Winarna, 2016) menyatakan bahwa kurangnya pengetahuan terkait rencana kerja dan laporan keuangan BumDes dapat diselesaikan melalui pemberian pelatihan untuk meningkatkan kapabilitas pengelola BUMDes, dimulai dengan perencanaan strategis, pemrograman, penganggaran, implementasi dan pengarahan pengelolaan keuangan BUMDes.

Lebih lanjut, (Junaid, Amiruddin, Muslim, \& Arham, 2019) juga menemukan permasalahan kurang terampilnya pengelola BUMdes mengelola keuangan dan mencatat transaksi membutuhkan pelatihan agar keterampilan mereka bertambah setelah kegiatan pengabdian ini dilakukan. Mendukung pernyataan (Junaid, Amiruddin, Muslim, \& Arham, 2019), (Nurhazana \& Wahyuni, 2020) menyatakan bahwa manajemen keuangan dan akuntansi BUMDesa berperan penting dalam menentukan realisasi tujuan organisasi.

\section{PELAKSANAAN DAN METODE}

\section{Pelaksanaan}

Pelaksanaan acara PKM dilakukan pada hari hari Rabu, 5 Februari 2020 di kantor desa Je'nemadinging dengan dihadiri oleh 2 orang perangkat desa, 5 orang pengelola dana desa dan akademisi STIEM Bongaya

Narasumber dalam kegiatan pengabdian ini adalah :

1. Sekretaris Desa Je'nemadinging

2. Asbi Amin, S.E., M.Ak (Dosen STIEM Bongaya)

3. Niken Probondani Astuti, ST., M.M (Dosen STIEM Bongaya) 


\section{METODE}

Metode yang digunakan PKM ini :
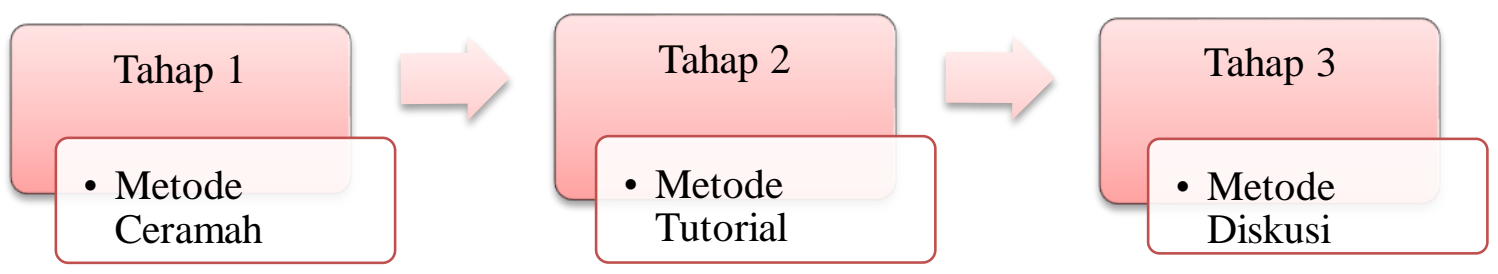

1. Metode Ceramah

\section{Gambar 2. Metode PKM}

Menyampaikan materi kepada peserta meliputi perkembangan BUMDes dan pengantar akuntansi BUMDes. Tahap pertama ini dilakukan selama 1 jam.

2. Metode Tutorial

Memberikan informasi akuntansi BUMDes kepada peserta, yaitu pembukuan di buku penagihan kas, buku pengeluaran kas, pembukuan di buku penjualan, pembukuan di buku pembelian, dan penyusunan laporan keuangan. Tahap ini diselenggarakan selama 4 jam.

3. Metode Diskusi

Metode ini diberikan kepada peserta agar terjadi proses interaktif melalui diskusi dan tanya jawab. Saat diskusi peserta dapat menyampaikan masalah yang dihadapi selama mengelola dana desa. Tahap ini diselenggarakan selama 1 jam.

Tabel 1. Pelaksanaan Kegiatan

\begin{tabular}{llll}
\hline No & Waktu & Materi & Narasumber \\
\hline 1 & $08.00-08.30$ & Pembukaan & \\
2 & $08.30-09.00$ & Sambutan Sekretaris Desa & Sekretaris Desa \\
3 & $09.00-10.00$ & $\begin{array}{l}\text { Pengenalan Akuntansi } \\
\text { BUMDes }\end{array}$ & Asbi Amin, S.E., M.Ak \\
4 & $10.00-12.00$ & Pembukuan BUMDes & Asbi Amin, S.E., M.Ak \\
5 & $12.00-13.00$ & Ishoma & \\
6 & $13.00-15.00$ & $\begin{array}{l}\text { Pembukuan } \\
\text { (Lanjutan) } \quad \text { BUMDes }\end{array}$ & \\
7 & $15.00-16.00$ & Diskusi dan tanya Jawab & Asbi Amin, S.E., M.Ak \\
& & & Asbi Amin, S.E., M.Ak dan \\
8 & $16.00-16.30$ & Penutup & Niken Probondani Astuti, S.T., M.M \\
\hline
\end{tabular}

\section{HASIL DAN PEMBAHASAN}

Kegiatan pelayanan ini berjalan dengan lancar dan lancar karena terkait dengan peningkatan kebutuhan akan pemahaman tentang akuntansi keuangan Kebutuhan peningkatan pemahaman pembukuan keuangan BUMDes bagi pengelola BUMDes di Desa Je'nemadinging di Kabupaten Gowa. Kegiatan ini dilakukan dengan pendekatan klasikal pada saat materi pengenalan pengelolaan keuangan BUMDes dan pendekatan individual yang dilakukan pada saat metode diskusi agar peserta lebih interaktif untuk mengampaikan masalah apa yang dijumpai selama mengelola keuangan desa. Hal ini dilakukan agar tujuan PKM bisa efektif. 


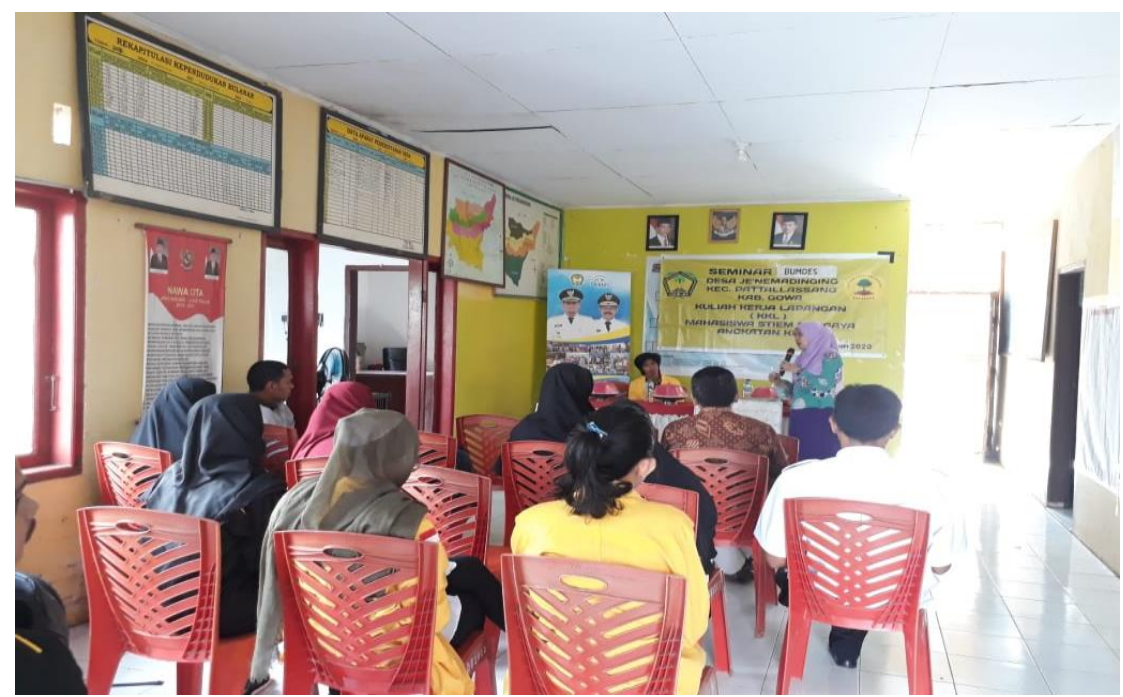

Gambar 3. Narasumber sedang menyampaikan materi PKM

Perubahan yang terjadi pada mitra setelah dilakukan PKM ini terlihat dari segi pengetahuan peserta yang sebelumnya tidak tahu tentang akuntansi BUMDes, setelah kegiatan ini peserta sudah tahu tentang akuntansi BUMDes, Bukan hanya pengetahuan tentang akuntansi, peserta juga telah memiliki pengetahuan tentang pengelolaan dan laporan keuangan BUMDes. Dilihat dari sisi keterampilan, para peserta sudah tahu membukukan kas masuk dan kas keluar, mencatat penjualan dan pembelian dan pengetahuan ini diperoleh setelah peserta mengikuti kegiatan ini.

Hasil PKM ini mendukung hasil Mahmudah (2018) yang menyatakan bahwa masih rendahnya pengetahuan pengelola BUMDes dan Aparatur Desa tentang pengelolaan BUMDes yang benar. Salah satu kesulitan pengelola BUMDes terletak pada tidak memadainya keterampilan dalam penatausahaan keuangan BUMDes. Umumnya pengelola keuangan BUMDes adalah pegawai yang tidak memiliki keahlian khusus (terutama akuntansi keuangan standar) (Kusmayadi, Firmansyah, \& Rahman, 2019). Melalui kegiatan PKM pengelola keuangan BUMDes telah memiliki keterampilan dalam penatausahaan dan pertanggungjawaban keuangan BUMDes sesuai dengan siklus akuntansi yang diterapkan. (Titioka, Huliselan, Sanduan, Ralahallo, \& Siahainenia, 2020).

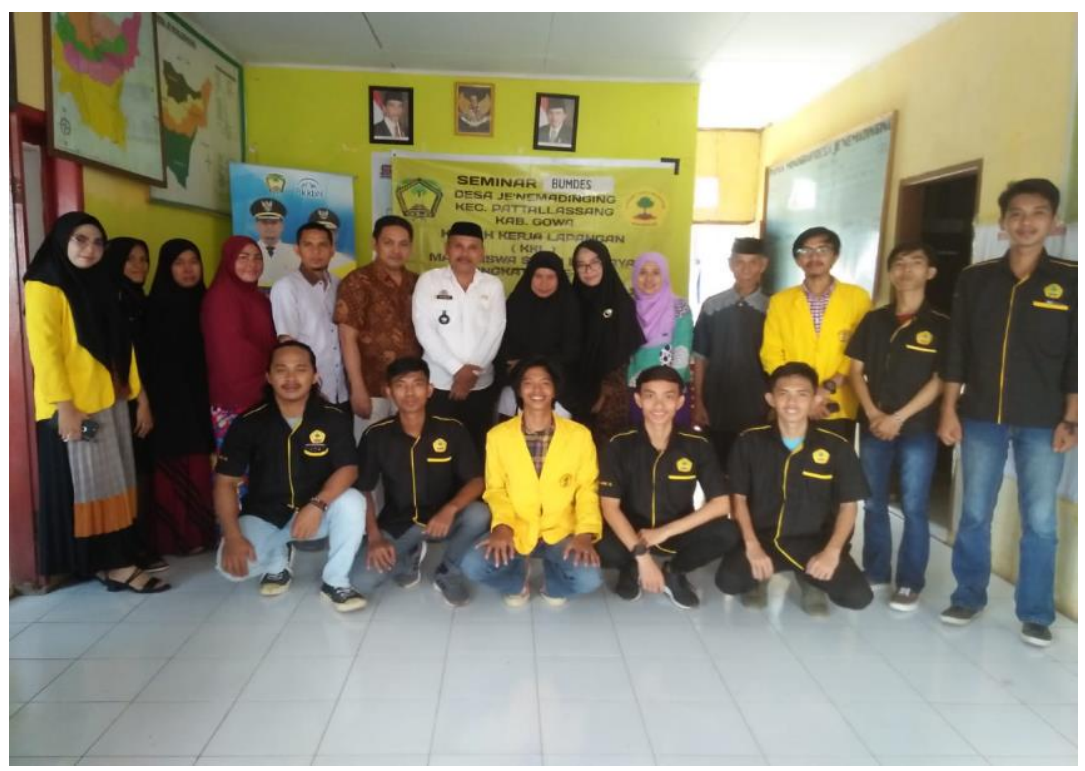

Gambar 4. Foto Bersama Setelah Acara Selesai

Beberapa faktor pendukung kegiatan PKM ini terlaksana dengan lancar adalah antusias dari peserta selama kegiatan. Pada saat yang sama, faktor-faktor yang membatasi keberhasilan acara tersebut meliputi:

1. Waktu yang terbatas. 
2. Keterbatasan alat-alat penunjang kegiatan seperti proyektor untuk presentasi, alat peraga, wifi dan audio.

\section{PENUTUP}

\section{Simpulan}

Pelaksanaan kegiatan PKM ini tidak terlepas dari upaya untuk mendukung program pemerintah meningkatkan kapasitas pengurus BUMDes. Dari hasil kegiatan PKM ini dapat disimpulkan bahwa

1. Pengurus BUMDes dapat melakukan pembukuan berupa pencatatan uang masuk dan uang keluar sesuai dengan aturan yang berlaku umum.

2. Pengurus BUMDes telah paham pembukuan pada pengeluaran kas, penerimaan kas, pembukuan pada buku penjualan, pembukuan pada buku pembelian dan penyusunan laporan keuangan.

\section{Saran}

Mengingat besarnya manfaat dari kegiatan PKM ini, maka disarankan untuk mengkomunikasikan rekomendasi kepada mitra kerja saat menyusun laporan keuangan :

1. Diperlukan pelatihan kepada para pengurus BUMDes agar mampu menerapkan pencatatan akuntansi sesuai standar yang berlaku bahkan mampu mengikuti perkembangan pelaporan melalu sistem Siskeudes.

2. Disarankan diadakan pendampingan agar pelaporan keuangan berkembang dan dapat dipertanggungjawabkan kepada masyarakat sekitarnya.

\section{DAFTAR PUSTAKA}

Anwar, A., \& Amin, A. (2020). Dimensi Karakteristik Laporan Keuangan Pemerintah. e-Jurnal Akuntansi. https://doi.org/10.33369/j.akuntansi.10.3.223-230, 10(3).

Ferina, Z. I., Hanila, S., Fitriano, Y., Susanti, N., \& Soleh, A. (2020). Peningkatan Pengelolaan Keuangan dan Akuntansi BUMDes Desa Pulau Panggung Kecamatan Talang Empat Bengkulu Tengah. Jurnal Pengabdian Masyarakat Bumi Rafflesia, 3(1).

Junaid, A., Amiruddin, A., Muslim, M., \& Arham, M. (2019). PKM Pendampingan Bimbingan Teknis Administrasi Keuangan Badan Usaha Milik Desa (Bumdes). Jurnal Pengabdian Bina Ukhuwah, 1(2).

Kusmayadi, D., Firmansyah, I., \& Rahman, R. (2019). IbBM Penyusunan Laporan Keuangan Keuangan BUMDes dan Koperasi Nelayan di Desa Sancang Kabupaten Garut. Jurnal Pengabdian Siliwangi, 5(1).

Mahmudah, S. (2018). Akuntabilitas Laporan Keuangan Badan Usaha Milik Desa (Studi Kasus : BUMDes Desa Sungon Legowo Bungah Gresik). Jurnal Ecoprenuer, 1(2).

Mispiyanti. (2020, Oktober). Pelatihan dan Pendampingan Pengelolaan Keuangan BUMDes"Desa Makmur". Journal of Community Service and Empowerment, 1(1), 30-35.

Nugrahaningsih, P., Falikhatun, \& Winarna, J. (2016). Optimalisasi Dana Desa Dengan Pengembangan Badan Usaha Milik Desa (Bum Des) Menuju Desa Mandiri. JAB. Jurnal Akuntansi Bisnis, 16(1), 37-45.

Nurhazana, \& Wahyuni, E. S. (2020). Efektivitas Pengelolaan Keuangan dan Akuntansi Pada Badan Usaha Milik Desa (BUMDes) Dengan Pendekatan Goal Model. Jurnal IAKP, 1(1), 41-46.

Nurniah, Sukriah, \& Istiyana, A. (2019). IBM Pelatihan dan Pendampingan Penyusunan Laporan Keuangan Pada BUMDes ASSAMATURU. Prosiding Seminar Nasional Penelitian\&Pengabdian Kepada Masyarakat (pp. 389-394). Makassar: Politeknik Negeri Ujung Pandang. 
Suryani, A. (2018, Oktober). Akuntansi dan Pengelolaan Dana Desa (Studi Kasus Desa Sungai Gelam Kecamatan Sungai Gelam Kabupaten Muaro Jambi). J-MAS (Jurnal Manajemen dan Sains), 3(2).

Titioka, B. M., Huliselan, M., Sanduan, A., Ralahallo, F., \& Siahainenia, A. J. (2020, Juni). Pengelolaan Keuangan BUMDES di Kabupaten Kepulauan Aru. Jurnal Pengabdian Masyarakat JAMAK (Manajemen\&Akuntansi), 3(1).

Undang-Undang No.6. (2014). Republik Indonesia. Jakarta.

Wirsa, I., \& Prena, G. D. (2020). Keberadaan Bumdes Sebagai Pilar Pertumbuhan Ekonomi Desa Di Desa Telagatawang, Kecamatan Sidemen Karangasem. PARTA : Jurnal Pengabdian Kepada Masyarakat, 1(1), 7-12. 